\title{
DOES SEVOFLURANE AFFECT CEREBRAL AUTOREGULATION IN CHILDREN?
}

\author{
Gordon T.C. Wong FANZCA, Igor Luginbuehl MD, Cengiz Karsli MD, Mirko Dolci MD,
} Bruno Bissonnette MD

Department of Anaesthesia, Hospital for Sick Children, Toronto

\section{INTRODUCTION}

The transient hyperemic response (THR) test is a simple non invasive technique which evaluates cerebral autoregulation using transcranial Doppler. The THR ratio (THRR) provides an index of cerebral autoregulation in healthy and head injured adults(1). We aim to evaluate this response in children undergoing general anesthesia using sevoflurane.

\section{METHODS}

After obtaining Research Ethics Committee approval and informed consent, ASA 1 children undergoing elective urological surgery were recruited. Each patient received sevoflurane at 0.5, 1.0 and $1.5 \mathrm{MAC}$ in random order. Analgesia was provided by caudal anesthesia using $0.25 \%$ bupivacaine without epinephrine. The middle cerebral artery flow velocities before (F1), during (F2) and after (F3) ipsilateral carotid artery compression were recorded. THRR is calculated by dividing $\mathrm{F} 3$ by $\mathrm{F} 1$.

\section{RESULTS}

To date 10 male children aged between 1.4 to 3.2 yrs $(1.5+/-0.7)$ have been recruited. Results are presented as means (SD) in the following table.

\begin{tabular}{|l|l|l|l|}
\hline & $0.5 \mathrm{MAC}$ & $1.0 \mathrm{MAC}$ & $1.5 \mathrm{MAC}$ \\
\hline $\mathrm{F} 1 \mathrm{~cm} / \mathrm{s}$ & $120(20)$ & $126(19)$ & $125(26)$ \\
\hline $\mathrm{F} 3 \mathrm{~cm} / \mathrm{s}$ & $153(26)$ & $147(25)$ & $147(30)$ \\
\hline THRR & $1.28(0.11)$ & $1.18(0.1)$ & $1.16(0.07)$ \\
\hline Range & 1.12 to 1.52 & 1.05 to 1.38 & 1.04 to 1.28 \\
\hline
\end{tabular}

The THRR is statistically different between $0.5 \mathrm{MAC}$ versus 1.0 \& $1.5 \mathrm{MAC}$ respectively. However, no difference was detected between 1.0 and 1.5 MAC.

\section{DISCUSSION}

THRR greater than 1.10 has previously been adopted as a lower limit of a normal response (1). Preliminary results in this study suggest that THR is maintained up to $1.5 \mathrm{MAC}$ of sevoflurane, but is reduced in the higher concentrations. This suggests that THR, and hence cerebral autoregulation, is affected by sevoflurane in a dose dependent fashion. More patients are presently being studied to further elucidate this response in children.

\section{REFERENCES}

1) J Neurosurg 1997; 86: 773-778 